\title{
Residues in the C-terminal region of activin A determine specificity for follistatin and type II receptor binding
}

\author{
W H Fischer, M Park, C Donaldson, E Wiater, J Vaughan, \\ L $\mathbf{M}$ Bilezikjian and $\mathbf{W}$ Vale
}

The Clayton Foundation Laboratories for Peptide Biology, The Salk Institute, 10010 N Torrey Pines Road, La Jolla, California 92037, USA

(Requests for offprints should be addressed to W H Fischer; Email: fischer@salk.edu)

\begin{abstract}
Activin is a secreted growth factor that signals by binding two related classes of single transmembrane receptors at the cell surface. The interaction of activin with its receptors is highly regulated by other cell surface receptors, antagonistic ligands, and high affinity extracellular binding proteins such as follistatin. Two activin A mutants, the deletion mutant des[85-109]-activin A and the point mutant K102E-activin A (K102E), were investigated with respect to their ability to bind cell surface receptors and the binding protein follistatin. The deletion mutant exhibits low affinity for both receptors
\end{abstract}

and follistatin whereas the point mutant fails to bind cell surface receptors but binds follistatin-288 with high affinity. K102E is able to compete with wild type activin to bind to follistatin and can thus increase the concentration of activin available for receptor binding and signaling. These findings underline the importance of the C-terminal region of activin for binding interactions and show that different residues in this region are involved in cell surface receptor and follistatin interactions.

Journal of Endocrinology (2003) 176, 61-68

\section{Introduction}

Activin $\mathrm{A}$ is a member of the transforming growth factor beta (TGF- $\beta$ ) superfamily of growth and differentiation factors. Besides its effects on growth and differentiation in many tissue types, activin A also plays a role in reproduction by regulating follicle-stimulating hormone (FSH) release from the pituitary. Activin A is a homodimer consisting of two disulfide-linked polypeptide chains, termed $\beta_{\mathrm{A}}$, of 116 amino acids in length (Vale et al. 1986). It signals through two classes of single transmembrane cell surface receptors which possess a cytosolic serine/ threonine kinase domain. Activin A binds initially to the type II receptor (ActRII) (Mathews \& Vale 1991). The type I receptor is then recruited into this complex and a cross-phosphorylation event takes place in which the type I receptor is phosphorylated in its intracellular domain by the type II receptor (ten Dijke et al. 1994, Wrana et al. 1994). The type I receptor, in turn, phosphorylates downstream signaling molecules known as SMADs (Wrana \& Attisano 2000).

The three-dimensional structures of several activin-like members of the TGF- $\beta$ superfamily in complex with the extracellular domains (ectodomains, ecd) of their receptors have recently been solved. These include bone morphogenic protein-2 (BMP2) in complex with its type I receptor ectodomain (Kirsch et al. 2000), BMP7 in complex with the activin receptor type II ectodomain (Greenwald et al., personal communication), and TGF- $\beta 3$ in complex with its type II receptor ectodomain (Hart et al. 2002). Evidence from mutation data on the ActRIIecd suggests that the interaction of activin with its type II receptor is similar to that observed in the BMP7ActRIIecd complex. This interaction involves a hydrophobic pocket on the concave surface of the ActRIIecd and residues on the ligand's 'fingers' - two pairs of antiparallel $\beta$-strands extending from the disulfide-linked core of the structure. Each of the monomeric subunits of the ligand interacts with one type II receptor ectodomain.

Activin's access to its receptors is regulated by a number of high and low affinity extracellular binding proteins (Phillips 2000, Phillips \& de Kretser 1998). The most important one of these is follistatin (Ueno et al. 1987), which binds activin with sub-nanomolar affinity and renders it unable to interact with receptors (Nakamura et al. 1990). Follistatin is a glycoprotein and exists in two splice variants, FS288 and FS315. Different functions have been proposed for these two variants. FS315 is the predominant circulatory form (Schneyer et al. 1996) whereas FS288 associates with the cell surface and is involved in activin internalization and degradation (Hashimoto et al. 1997). Both mechanisms lead to a diminished bio-availability of activin. The activinfollistatin complex is thought to consist of one activin 
dimer and two follistatin molecules (Shimonaka et al. 1991).

Although a clearer picture of the interaction of activin with its cell surface receptors is emerging, it is not understood which parts of the ligand interact with follistatin. For this study we generated both deletion and point mutants of activin to determine whether similar regions are involved in the interaction with signaling cell surface receptors and the extracellular regulatory protein follistatin. Mutants that exhibit specificity for one class of binding protein would be useful tools for the modulation of activin bio-availability.

Selection of the mutant activins investigated in this study was based on our survey of activin mutants in which predicted surface regions were deleted. Of these, a mutant with a deletion in the C-terminal portion, predicted to form an extended beta structure, exhibited the lowest biological activity. A point mutation in this region described by Wuytens et al. showed low biological affinity but was able to bind to follistatin as shown in cross-linking experiments (Wuytens et al. 1999). Here we investigate the actions of the deletion and point mutants with respect to their binding affinities and their behavior in biological assay systems.

\section{Materials and Methods}

\section{Mutagenesis and protein expression}

To generate the [85-109] deletion mutant, a PCR mutagenesis procedure using the ExSite (Stratagene, La Jolla, CA, USA) kit was employed. A FLAG epitope sequence was added to the $N$-terminus of the mature activin $\beta_{A}$ sequence by replicating the entire plasmid including its insert and adding the FLAG sequence between residues G1 and L2 of the mature activin sequence. This plasmid (pGem3zf(-), Promega, Madison, WI, USA) was used as a substrate for successive PCRs to introduce deletion or point mutations. The deletion mutant was generated with an antisense primer starting at the site corresponding with T84 and a sense primer starting at V110. In order to maintain high fidelity of the PCR, approximately 0.1 unit of cloned Pfu DNA Polymerase (Stratagene) in addition to 5 units of Taq DNA Polymerase (New England Biolabs) was used. Twelve cycles of PCR were performed under high stringency conditions. The PCR mixture was then treated with endonuclease Dpn 1 to remove parental plasmids. The mutated cDNA was subcloned into the expression vector (pVL1392, Invitrogen) and the expression was carried out by standard baculovirus protocols.

Mutagenesis of K102E mutant activin was carried out using an oligonucleotide primer designed to contain a point mutation, where the lysine codon (AAA) was altered to a glutamic acid codon (GAA). The sequences of this and all other plasmids were confirmed by dideoxy sequencing. The cDNA containing K102E mutation was subcloned into a baculovirus transfer vector (pVL1392, Invitrogen) and transfected into Sf9 insect cells (Invitrogen) along with linearized BaculoGold DNA (Pharmingen, La Jolla, CA, USA). Resulting recombinant virus was used to express the mutant protein in High 5 insect cells.

Since the mutant protein is a secreted recombinant protein, conditioned media were harvested, filtered and purified using batch purification with anti-FLAG M2-agarose affinity gel (Sigma). This was followed by reversed phase HPLC purification. The amount of protein was quantitated by comparing the peak area to that of wild type activin A (which had previously been quantified by amino acid analysis) in a separate HPLC analysis. Purities were estimated, from both HPLC and SDS-PAGE analysis, to be in excess of $95 \%$. The intact molecule mass was determined by MALDI-MS (matrix-assisted laser desorption ionization mass spectrometry) analysis on an ABIPerseptive DE-STR mass spectrometer in the linear mode employing sinapinic acid as the matrix.

\section{Biological activity (FSH release) assay}

Biological activity of the mutant activins was assessed by their ability to promote the release of FSH from rat anterior pituitary cells in primary culture. The details of this assay are described elsewhere (Vale et al. 1983). Briefly, anterior pituitary cells from male Sprague-Dawley rats were dispersed with collagenase and plated in 48-well plates $\left(0 \cdot 15 \times 10^{6}\right.$ cells per well). After a $72 \mathrm{~h}$ recovery in complete medium ( $\beta \mathrm{PJ}$ ) supplemented with $2 \%$ fetal bovine serum (FBS) and appropriate growth factors (Vale et al. 1983), the cells were washed three times with the same medium and treated for $72 \mathrm{~h}$, as indicated. The secretion of FSH was quantified by radioimmunoassay using kits generously provided by the National Pituitary and Hormone Distribution Program of the National Institute of Diabetes and Digestive and Kidney Diseases (NIDDK).

\section{ActRII binding assay}

Receptor binding was determined by employing the human erythroleukemia cell line K562 stably transfected with ActRII and activin receptor-like kinase (ALK4) (KAR6 cells) (Lebrun \& Vale 1997). Receptor expression in these cell lines is controlled by a lac repressor/ promoter system and therefore is isopropyl $\beta-\mathrm{D}-1-$ thiogalactopyranoside (IPTG)-inducible. Cells were grown in suspension culture in RPMI 1640 medium supplemented with 10\% FBS and $2 \mathrm{mM}$ glutamine. Induction was achieved by addition of $1 \mathrm{mM}$ IPTG $16 \mathrm{hr}$ prior to the assay. Cells were isolated by centrifugation and washed twice in binding buffer (HDB [137 mM NaCl, $5 \mathrm{mM} \mathrm{KCl}, 0 \cdot 7 \mathrm{mM} \mathrm{Na} 2 \mathrm{HPO}_{4}, 25 \mathrm{mM}$ HEPES, $100 \mu \mathrm{g} /$ $\mathrm{mL}$ gentamycin, $\mathrm{pH} 7 \cdot 4]$ supplemented with $5 \mathrm{mM}$ $\mathrm{MgSO}_{4}, 1.6 \mathrm{mM} \mathrm{CaCl} 2,1 \mathrm{mg} / \mathrm{mL}$ BSA). Binding was 
carried out in microcentrifuge tubes with $1-2 \times 10^{6}$ cells per tube in the presence of a constant amount of ${ }^{125} \mathrm{I}-$ labeled activin A (50 fmol $=\sim 100000$ c.p.m.) and varying concentrations of activin A mutant or wild type proteins in a total volume of $100 \mu \mathrm{l}$. After incubation at room temperature for $90 \mathrm{~min}$, the tubes were placed on ice and $1 \mathrm{ml}$ of ice-cold binding buffer was added. This was followed by centrifugation to separate the cell pellet. The supernatant was aspirated, the bottom of the tube containing the pellet was cut off and c.p.m. from bound ligand were determined.

\section{Follistatin binding assay}

The follistatin binding assay employed a polyclonal antiserum against follistatin that binds the protein with high affinity but does not interfere with its binding to activin (Bilezikjian \& Vaughan, unpublished observations). The antiserum against follistatin (PBL \#5542, 8/21/95 bleed) was raised in our laboratory in rabbit using recombinant human FS288 (rhFS288) produced by Chinese hamster ovary cells (Inouye et al. 1991), purified and provided by Dr Nicholas Ling (Neurocrine, La Jolla, CA, USA) under contract with National Institute of Child Health and Human Development (NICHD). The rhFS288 antigen was a heterogenous preparation of non-glycosylated, mono-glycosylated and di-glycosylated forms of 31, 35 and $40 \mathrm{kDa}$ rhFS288.

rhFS288 (1-2 ng) was incubated with a constant amount of ${ }^{125}$ I-labeled activin A (20 fmol $=40000$ c.p.m.) and varying concentrations of mutant or wild type activin $\mathrm{A}$ in the presence of the anti-follistatin antibody (1:500 final dilution). Binding was carried out in a volume of $100 \mu \mathrm{l}$ at room temperature for $90 \mathrm{~min}$. After this time, the tubes were chilled on ice and normal rabbit serum (1:300 final dilution) and sheep anti-rabbit IgG (1:200 final dilution) were added. After an additional $30 \mathrm{~min}$, PEG was added (7\% final concentration) and the precipitate was collected by centrifugation after $30 \mathrm{~min}$ of incubation on ice. The supernatant was aspirated and the bottoms of the tubes were cut off and bound counts were quantified.

\section{p15-Luciferase assay in Hep G2 cells}

Tissue culture and generation of HepG2 cell line stably transfected with p15 HepG2 cells (obtained from American Type Culture Collection, Manassas, VA, USA, ATCC\# HB-8065) were cultured in 90\% (v:v) $\alpha$-MEM (Mediatech, Herndon, VA, USA) $/ 10 \%$ FBS (Gemini Bioproducts, Calabasas, CA, USA) at $37^{\circ} \mathrm{C}$ in $5 \% \mathrm{CO}_{2}$. Every 4 days cells were dispersed with trypsin and equal numbers of cells were transferred to new dishes. Viable cells were counted in a hemocytometer using trypan blue exclusion staining. Stable cell lines were generated by transfecting HepG2 cells with linearized DNA at a ratio of $9 \mu \mathrm{g}$ pcDNA3·1-Hygromycin (Invitro- gen) to $1 \mu \mathrm{g}$ of $\mathrm{p} 15^{\text {(INK4B) }}$ promoter-pGL2-Basic (provided by Dr X-F Wang, Duke University, Raleigh, NC, USA) (Li et al. 1995) by electroporation. Transfected cells were selected by culture in $250 \mu \mathrm{g} / \mathrm{ml}$ Hygromycin-B. After 3 weeks individual colonies were selected. The stable clone HepG2-p15.1 was routinely cultured without Hygromycin-B with no loss of luciferase activity or Hygromycin-B resistance, even after more than 4 months in culture.

Luciferase assays in the HepG2-p15.1 stable cell line For luciferase assays, HepG2-p15. 1 cells were plated at $0 \cdot 5$ x $10^{4}$ per well in 48 -well plates in $200 \mu$ l 90\% $\alpha$-MEM/ $10 \%$ FBS. Treatments were added in triplicate for $18 \mathrm{~h}$ in a final volume of $100 \mu$ with $\alpha$-MEM/10\% FBS as vehicle. Luciferase harvest and assay were carried out as follows: Cells were rinsed with $250 \mu$ Hepes dissociation buffer $(\mathrm{HDB})$ and lysed on the plate by adding $100 \mu \mathrm{l}$ of luciferase assay lysis buffer $(25 \mathrm{mM}$ HEPES $\mathrm{pH} 7 \cdot 8$, $10 \mathrm{mM} \mathrm{MgCl}_{2}, 5 \mathrm{mM}$ EGTA, 1\% Triton-X-100) per well and incubating on a tilting platform shaker for $20 \mathrm{~min}$ at $4{ }^{\circ} \mathrm{C}$. For luciferase assays $20 \mu \mathrm{l}$ of lysate was injected with $100 \mu \mathrm{l}$ of luciferin dilution buffer $(25 \mathrm{mM}$ HEPES $\mathrm{pH} 7 \cdot 8,10 \mathrm{mM} \mathrm{MgCl}_{2}, 5 \mathrm{mM}$ EGTA, $1 \mathrm{mM}$ ATP, $0.25 \mathrm{mM}$ luciferin) in a luminometer and light emission was measured for ten seconds after a two second delay. Relative luminometer units were recorded and statistical analysis was performed employing Prism (version 3.0) using non-linear regression and sigmoidal dose-response parameters.

\section{Statistical analyses}

For all assays described above, the data points were determined in triplicate. Statistical analyses were performed employing the GraphPad Prism program (San Diego, CA, USA), version 3.0. Binding assays were analysed using non-linear regression parameters for onesite competition. For activity assays, non-linear regression parameters for a sigmoidal dose-response were used. The error bars in the graphs represent S.E.M. Each assay was carried out at least three times.

\section{Results}

Deletion mutant des[85-109]-activin A exhibits low affinity for follistatin and cell surface receptors

To examine regions of activin A that are involved in interaction with cell surface receptors and other binding proteins, a series of activin mutants was generated in which predicted surface regions were deleted. The predictions were made based on homology to TGF- $\beta$ (Daopin et al. 1992, Schlunegger \& Grütter 1992) and BMP (Griffith et al. 1996, Scheufler et al. 1999) molecules for 

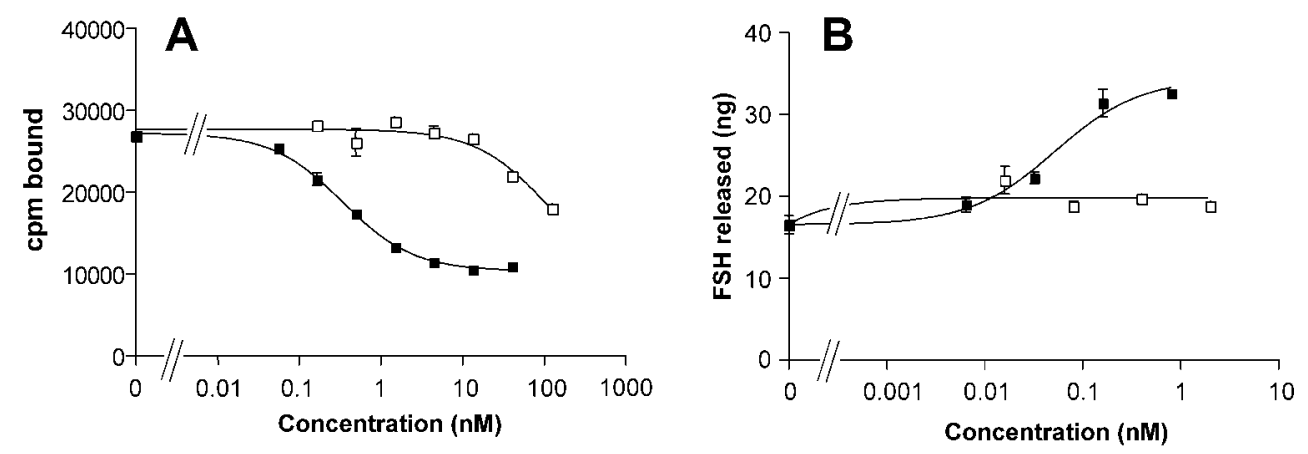

Figure 1 (A) Receptor binding assay. Displacement of ${ }^{125}$ I-activin A from KAR6 cells by activin A ( $\left.\mathbf{\square}\right)$ and by des[85-109]-activin A $(\square)$. Whole cells were precipitated by centrifugation to separate bound from free ligand. (B) FSH release from rat anterior pituitary cells by the [85-109] deletion mutant. Rat anterior pituitary cells in primary culture were treated for $72 \mathrm{~h}$ with activin $\mathrm{A}(\boldsymbol{\square})$ or des[85-109]-activin $\mathrm{A}(\square)$. FSH release was quantified by radioimmunoassay. Data points were determined in triplicate and error bars represent S.E.M.

which three-dimensional structures were available. The deletions were introduced in regions of the molecule that would minimize overall structural disturbance, i.e. outside the disulfide linked core of the dimer. Three of these deletion mutants, des[1-9]-C12S-activin A, des[21-32]activin A and des[68-75]-activin A, exhibited FSH releasing bioactivity with less than a tenfold reduction in potency compared with activin A. A fourth deletion mutant, des[85-109]-activin A, exhibited the lowest biological activity as assessed by its ability to release FSH from rat anterior pituitary cells (Fig. 1B). The receptor binding affinity of the mutant, as measured by its ability to compete with radiolabeled activin A for binding to cells stably transfected with ActRII and ALK4 (Lebrun \& Vale 1997), was found to be very low $\left(\mathrm{EC}_{50}>100 \mathrm{nM}\right)$ (Fig. 1A). Competition binding to follistatin (FS288) was also found to be low $\left(\mathrm{EC}_{50}>100 \mathrm{nM}\right)$ (Fig. 2). This region of

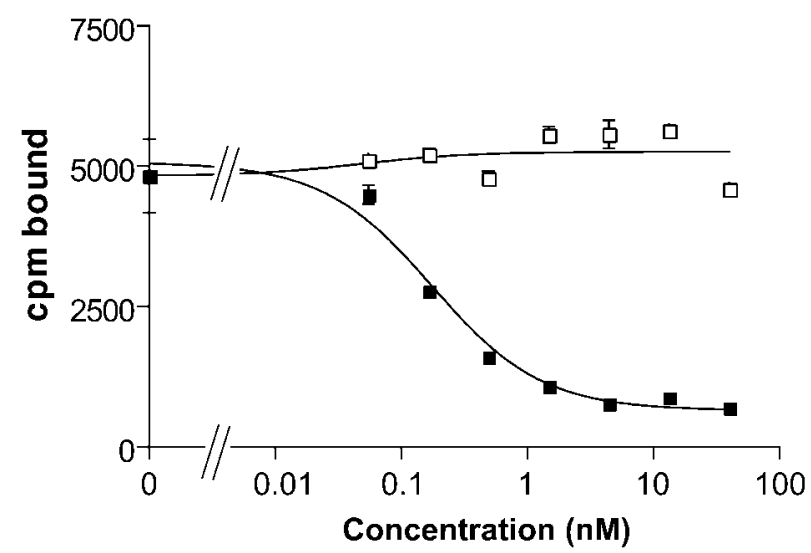

Figure 2 Follistatin binding assay of the [85-109] deletion mutant. Displacement of ${ }^{125}$ I -activin A from FS288 by activin A $(\square)$ and by des[85-109]-activin $A(\square)$. Follistatin-activin complexes were immunoprecipitated to separate bound from free ligand. Data points were determined in triplicate and error bars represent S.E.M. the ligand is therefore likely to contain major binding determinants for both the cell surface receptors as well as for follistatin.

Point mutant K102E exhibits high affinity for follistatin but low affinity for type II receptor

An activin point mutant that exhibited low biological activity but was able to bind to follistatin in cross-linking experiments was identified by Wuytens et al. (1999). The point mutation, which replaces a positively charged lysine in position 102 with a negatively charged glutamic acid, is in the region absent in the deletion mutant described above. We generated microgram quantities of this mutant. The binding affinity of the K102E mutant to cell surface receptors was greatly reduced (Fig. 3A) as was its ability to release FSH from rat anterior pituitary cells (Fig 3B). This demonstrates the importance of the long C-terminal 'finger' in receptor interactions. In contrast, the affinity of the point mutant for follistatin was reduced by less than one order of magnitude compared with wild type activin $\mathrm{A}$, and was determined to be in the nanomolar range (Fig. 4).

\section{K102E competes with wild type activin A for follistatin binding}

Activin bound to follistatin is not available for receptor binding and does not contribute to signaling events (Inouye et al. 1991). It was therefore investigated if K102E could increase the concentration of wild type activin A in a system where competition between signaling receptors and soluble follistatin occurs. In most activin-responsive systems, follistatin is present in either its membraneassociated or soluble form. A mutant such as K102E that binds follistatin with nanomolar affinity yet exhibits low receptor affinity could therefore be used to compete for 

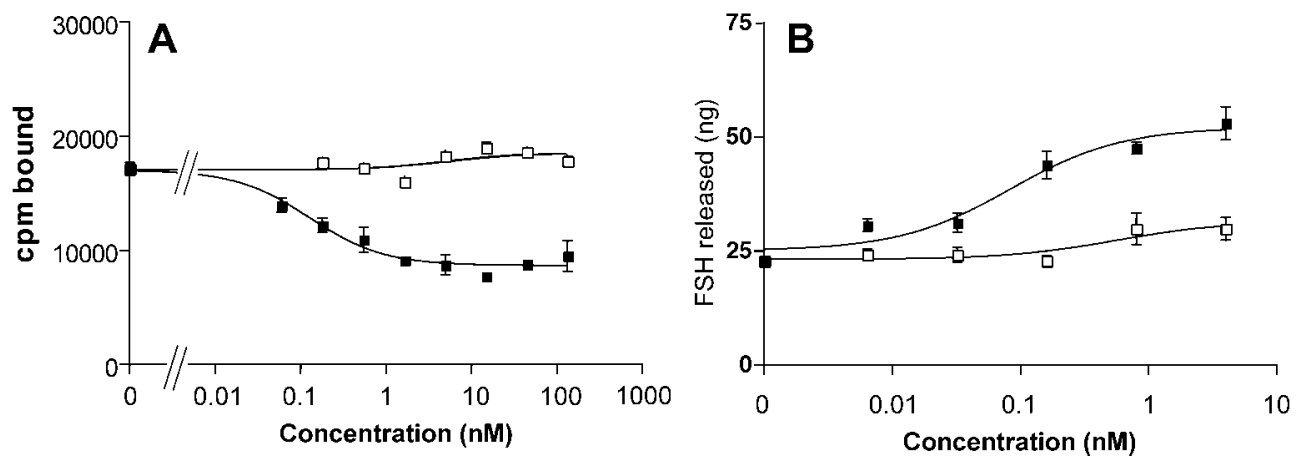

Figure 3 (A) Displacement of ${ }^{125}$ I-activin A from KAR6 cells by activin A $(\square)$ and by K102E $(\square)$. Whole cells were precipitated by centrifugation to separate bound from free ligand. (B) FSH release from rat anterior pituitary cells in primary culture treated for $72 \mathrm{~h}$ with activin $\mathrm{A}(\boldsymbol{\square})$ or K102E $(\square)$. FSH release was quantified by radioimmunoassay. Data points were determined in triplicate and error bars represent S.E.M.

follistatin binding sites and liberate wild type activin sequestered in such a complex. Follistatin and activin form a 2:1 (molar ratio) complex (Shimonaka et al. 1991). The ability of the K102E mutant to release FSH from rat anterior pituitary cells was therefore tested in the presence of a constant ratio of FS288 and wild type activin A. As controls, constant concentrations of either follistatin or submaximal doses of activin A were added. The mutant by itself exhibited low, but significant, FSH releasing bioactivity $(P<0.02$ at $4 \mathrm{nM})$. As expected, activin A $(0.2 \mathrm{nM})$ and follistatin $(0.5 \mathrm{nM})$ stimulated and inhibited FSH release from rat anterior pituitary cells, respectively (Fig. 5). Basal FSH release was also suppressed in the presence of a constant ratio of activin:follistatin $(0 \cdot 2: 0 \cdot 5 \mathrm{nM})$. The K102E mutant did not significantly modify the effect of a constant concentration of activin A alone. However its presence did stimulate FSH release in a concentration-dependent manner when added to rat

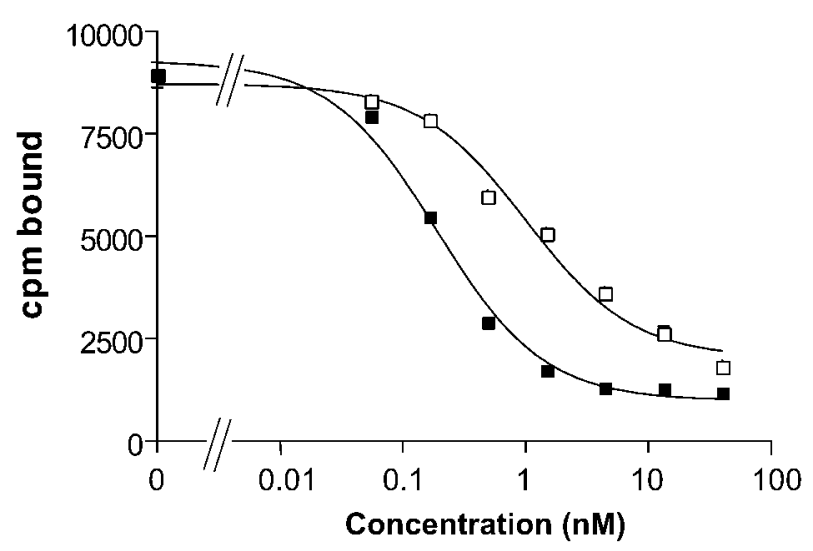

Figure 4 Follistatin binding assay of K102E. Displacement of ${ }^{125}$ I-activin A from FS288 by activin A ( $\square$ ) and by K102E ( $\square$ ). Follistatin-activin complexes were immunoprecipitated to separate bound from free ligands. Data points were determined in triplicate and error bars represent S.E.M. anterior pituitary cells along with either follistatin alone or a constant amount of activin:follistatin complex at doses $>2 \mathrm{nM}(P<0 \cdot 02)$ (Fig. 5). This indicates that K102E can liberate wild type activin that is complexed with follistatin and thus increase the effective activin concentration.

Primary cultures of rat anterior pituitary cells are known to secrete both activin and follistatin into the medium (Bilezikjian et al. 1993a,b). The possibility therefore arose that the increase in FSH release observed in the presence of the K102E mutant was caused by the displacement of activin from the endogenous activin-follistatin complex in this system. To investigate this further, we employed an artificial activin-responsive system consisting of the human liver cell line, HepG2, stably transfected with the activin responsive $\mathrm{p} 15$ promoter ( $\mathrm{Li}$ et al. 1995) fused to the luciferase gene. These cells respond to activin by producing luciferase which can be conveniently assayed. Wild

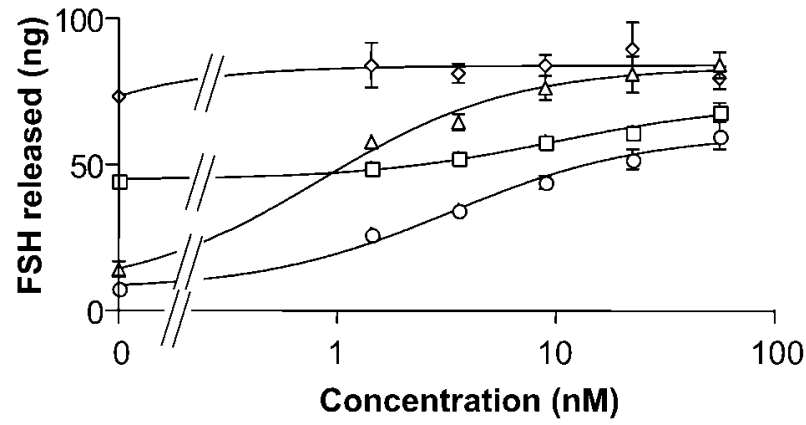

Figure $5 \mathrm{FSH}$ release from rat anterior pituitary cells in primary culture treated for $72 \mathrm{~h}$ with the $\mathrm{K} 102 \mathrm{E}$ mutant in the presence and absence of activin A and follistatin. K102E mutant alone ( $\square$ ). $\mathrm{K} 102 \mathrm{E}$ in the presence of a constant concentration of follistatin $(0.5 \mathrm{nM})(\mathrm{O}) . \mathrm{K} 102 \mathrm{E}$ in the presence of a constant concentration of activin $\mathrm{A}(0 \cdot 2 \mathrm{nM})(\diamond)$. K102E in the presence of a constant concentration of activin $\mathrm{A}(0 \cdot 2 \mathrm{nM})$ and follistatin $(0 \cdot 5 \mathrm{nM})(\triangle)$. Data points were determined in triplicate and error bars represent S.E.M. 


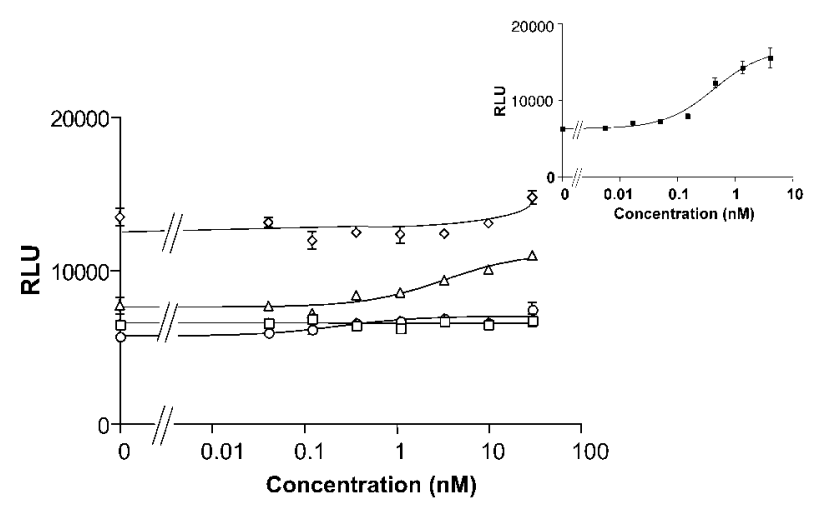

Figure 6 Luciferase activity assay. HepG2 cells stably transfected with a $\mathrm{p} 15$-Luc reporter construct were treated for $18 \mathrm{~h}$ with the K102E mutant in the presence and absence of activin A and follistatin. K102E mutant alone ( $\square$ ). K102E in the presence of a constant concentration of follistatin $(1 \cdot 2 \mathrm{nM})(\mathrm{O})$. K102E in the presence of a constant concentration of activin $\mathrm{A}(0.5 \mathrm{nM})(\diamond)$. $\mathrm{K} 102 \mathrm{E}$ in the presence of a constant concentration of activin A $(0.5 \mathrm{nM})$ and follistatin $(1.2 \mathrm{nM})(\triangle)$. The inset (top right) shows the effect of activin A by itself. RLU, relative luminometer units. Data points were determined in triplicate and error bars represent S.E.M.

type activin $\mathrm{A}$ stimulated luciferase activity with an $\mathrm{EC}_{50}$ of $394 \pm 106 \mathrm{pM}(n=4$, Fig. 6 inset). In this system, K102E was devoid of any significant activin-like activity (Fig. 6). A constant concentration of $1.2 \mathrm{nM}$ follistatin alone or together with a constant amount of activin A $(0.5 \mathrm{nM})$ did not have a great effect on baseline luciferase activity suggesting that endogenous activin does not significantly contribute to the basal luciferase activity, unlike the situation in rat anterior pituitary cells. The K102E-activin A mutant stimulated luciferase reporter activity when added to cells incubated with a constant ratio of activin: follistatin $(0 \cdot 5 / 1 \cdot 2 \mathrm{nM})$ with an $\mathrm{EC}_{50}$ of $2 \cdot 4 \pm$ $1.3 \mathrm{nM}(n=4)$ but not with follistatin alone (Fig. 6). Similar effects were observed in the assay regardless of whether or not the activin A-FS288 complex was preincubated for $8 \mathrm{~h}$ or not. Similar to rat pituitary cells, the K102E mutant did not have an effect on luciferase reporter activation in the presence of a constant submaximal concentration of activin A (Fig. 6).

These findings indicate strongly that K102E-activin A is able to compete with wild type activin for follistatin binding. Activin that has been engaged in a complex with follistatin can be liberated and become available for signaling interactions. The low, but significant, release of FSH observed in response to the point mutant in the pituitary cell assay is most likely a result of the mutant's ability to release endogenous activin from activinfollistatin complexes present in the rat anterior pituitary cell culture system. The low baseline of reporter gene expression in the HepG2 cell system indicates that such endogenous complexes do not play a significant role in this assay.

\section{Discussion}

Two activin A mutants that exhibit greatly impaired receptor binding affinity and low biological activity were investigated in this study. The deletion mutant, des[85109]-activin A, was able to bind to cells overexpressing activin receptors with an approximately 300 -fold reduced affinity (100 nM compared with $0.3 \mathrm{nM}$ for wild type activin A). Its ability to bind follistatin was similarly diminished. The point mutant, K102E (Wuytens et al. 1999), showed no measurable affinity for cell surface receptors but bound to FS288 with nanomolar affinity. It was therefore investigated whether the K102E point mutant could be employed to modulate the availability of wild type activin in biological systems. The bio-availability of activin is extensively regulated by a variety of factors (Phillips 2000). The propagation of a biological response requires ligand interaction with type II and type I cell surface receptors. Access to these receptors is regulated by the high affinity binding protein follistatin, of which one form (FS288) is thought to be mainly membraneassociated (Hashimoto et al. 1997) whereas the other (FS315) is thought to be the major circulatory form (Schneyer et al. 1996). Other regulatory events include the low affinity interaction with $\alpha_{2}$-macroglobulin (Vaughan \& Vale 1993) and the presence of a pseudo-type I receptor, BAMBI (Onichtchouk et al. 1999).

Both forms of follistatin bind activin with high affinity and diminish its biological activity (Inouye et al. 1991). This is likely to be due to the formation of a high affinity complex that is unable to interact with cell surface receptors. We employed two activin responsive systems to investigate the ability of the K102E mutant to compete for follistatin binding and thus increase the bio-active concentration of wild type activin. The well established rat anterior pituitary system responds to activin treatment by releasing FSH and has been employed extensively for investigating activin bio-activity. The K102E mutant by itself exhibited a low, but significant, activity in this assay. The fact that the bioactivity of the mutant was evident in the presence of FS288 or FS288-activin A suggests that the mutant displaced activin from endogenous or exogenous complexes. This primary cell culture assay system is likely to be a good representation of events in the anterior pituitary in vivo. Cultured rat anterior pituitary cells have been reported to secrete both activin and follistatin during the course of the $72 \mathrm{~h}$ assay (Bilezikjian et al. 1993a,b). The presence of endogenous amounts of activin and follistatin might explain the low but significant activity caused by the treatment with K102E by itself. The intrinsic activity observed would be unlikely given the extremely low receptor affinity of the mutant. To further investigate this question, an artificial activin-responsive cell culture system was used. The liver cell line HepG2 was stably transfected with the promoter of the activin-responsive p15 gene linked to a luciferase reporter construct. Activin A was 
able to stimulate luciferase activity approximately threefold in these cells after an $18 \mathrm{~h}$ treatment. In this system, the K102E mutant did not exhibit any activity. Addition of exogenous activin A and FS288 rendered the cells responsive to $\mathrm{K} 102 \mathrm{E}$ in a dose-dependent manner. It is not known how much, if any, activin or follistatin is secreted by the HepG2 cells. The lack of any luciferase activity through addition of K102E or FS288 alone suggests that the endogenous concentrations of activin and follistatin are low. In addition, the much shorter treatment time makes interference from endogenous quantities of these proteins less likely. In both cell culture systems, the K102E mutant can effectively compete for follistatin binding thus freeing up wild type activin in the endogenous or exogenous complexes.

The three-dimensional structure of activin is not known but is likely to be similar to those of other members of the TGF- $\beta$ superfamily. The BMPs and TGF- $\beta$ s are likely to share a cysteine bonding pattern with activin, that is known as the cystine knot motif. Each monomeric subunit of the ligands can be described as a hand from which two finger-like beta-sheets extend. The mutations described in this study are located in the more C-terminal long finger. The corresponding region in TGF- $\beta$ has been implicated in receptor binding (Qian et al. 1996). A number of contacts between ligand and receptor were also identified in this region in the recently solved structure of the BMP7-ActRIIecd complex (Greenwald et al., personal communication). The residue equivalent to the activin K102 is L125 in BMP7. In the complex, this residue is in close contact with a region of the ActRIIecd that has been identified as being important in activin binding (Gray et al. 2000). The introduction of a negative charge in the ligand at this location can explain the inability to bind, as a glutamic acid residue (E29) on the receptor side could cause electrostatic repulsion. The fact that the neutral substitution (leucine) in BMP7 enables the ligand to bind, whereas the neutral substitution in activin A (K102A, Wuytens et al. 1999) abolishes binding, indicates that other factors may play a role in the interaction. One possible explanation could involve steric requirements on both the receptor and ligand sides.

The interaction of activin with follistatin is not as well characterized as that with its type II receptors. There is evidence that one activin dimer binds two follistatin molecules (Shimonaka et al. 1991). We had previously found that a monomeric activin mutant, [Ser80]-activin A, had greatly diminished affinity for follistatin but high affinity for type II receptors (Fischer et al. 1995, Hüsken-Hindi et al. 1994). Evidence has been presented that two distinct domains of follistatin are involved in activin binding (Sidis et al. 2001, Wang et al. 2000). Our finding that the des[85-109]-activin A deletion mutant has greatly diminished follistatin binding affinity indicates that this region is either directly involved in the interaction or lies close to the interaction site. The high affinity of the
K102E mutant for FS288 indicates that this particular residue is not essential for the interaction. Further mutagenesis studies are required to elucidate the activinfollistatin interaction in more detail.

\section{Acknowledgments}

We would like to thank Dr Soon Lee for discussions and help with statistical analyses and Mr Minh Phan for his assistance in cell culture and assay procedures. This work was supported by NIH grant HD13527, the Robert J and Helen C Kleberg Foundation and supported in part by The Foundation for Medical Research, Inc. W V is a Senior FMR, Inc. investigator.

\section{References}

Bilezikjian LM, Corrigan AZ, Vaughan JM \& Vale WW 1993 a Activin-A regulates follistatin secretion from cultured rat anterior pituitary cells. Endocrinology 133 2554-2560.

Bilezikjian LM, Vaughan JM \& Vale WW 1993 b Characterization and the regulation of inhibin/activin subunit proteins of cultured rat anterior pituitary cells. Endocrinology 133 2545-2553.

Daopin S, Piez KA, Ogawa Y \& Davies DR 1992 Crystal structure of transforming growth factor- $\beta 2$ : an unusual fold for the superfamily. Science 257 369-373.

ten Dijke P, Yamashita H, Ichijo H, Franzen P, Laiho M, Miyazono K \& Heldin CH 1994 Characterization of type I receptors for transforming growth factor-beta and activin. Science 264 101-104.

Fischer WH, Vaughan J, Hüsken-Hindi P, Park M \& Vale W 1995 The intermolecular disulfide bond in activin is required for high affinity binding to follistatin. 77th Annual Meeting of the Endocrine Society, Washington DC, USA (Abstract).

Gray PC, Greenwald J, Blount AL, Kunitake KS, Donaldson CJ, Choe S \& Vale W 2000 Identification of a binding site on the type II activin receptor for activin and inhibin. Journal of Biological Chemistry 275 3206-3212.

Griffith DL, Keck PC, Sampath TK, Rueger DC \& Carlson WD 1996 Three-dimensional structure of recombinant human osteogenic protein 1: structural paradigm for the transforming growth factor beta superfamily. PNAS 93 878-883.

Hart PJ, Deep S, Taylor AB, Shu Z, Hinck CS \& Hinck AP 2002 Crystal structure of the human TbetaR2 ectodomain-TGF-beta3 complex. Nature Structural Biology 9 203-208.

Hashimoto O, Nakamura T, Shoji H, Shimasaki S, Hayashi Y \& Sugino H 1997 A novel role of follistatin, an activin-binding protein, in the inhibition of activin action in rat pituitary cells. Endocytotic degradation of activin and its acceleration by follistatin associated with cell-surface heparan sulfate. Journal of Biological Chemistry 272 13835-13842.

Hüsken-Hindi P, Tsuchida K, Park M, Corrigan AZ, Vaughn J, Vale W \& Fischer WH 1994. Monomeric activin A retains high receptor binding affinity but exhibits low biological activity. Journal of Biological Chemistry 269 19380-19384.

Inouye S, Guo Y, Ling N \& Shimasaki S 1991 Site-specific mutagenesis of human follistatin. Biochemical and Biophysical Research Communications 179 352-358.

Kirsch T, Sebald W \& Dreyer MK 2000 Crystal structure of the BMP-2-BRIA ectodomain complex. Nature Structural Biology 7 492-496.

Lebrun JJ \& Vale WW 1997 Activin and inhibin have antagonistic effects on ligand-dependent heterodimerization of the type I and type II activin receptors and human erythroid differentiation. Molecular and Cellular Biology 17 1682-1691. 
Li JM, Nichols MA, Chandrasekharan S, Xiong Y \& Wang XF 1995 Transforming growth factor beta activates the promoter of cyclin-dependent kinase inhibitor p15 INK4B through an Sp1 consensus site. Journal of Biological Chemistry 270 26750-26753.

Mathews LS \& Vale WW 1991 Expression cloning of an activin receptor, a predicted transmembrane serine kinase. Cell 65 973-982.

Nakamura T, Takio K, Eto Y, Shibai H, Tatani K \& Sugino H 1990 Activin-binding protein from rat ovary is follistatin. Science $\mathbf{2 4 7}$ 836-838.

Onichtchouk D, Chen YG, Dosch R, Gawantka V, Delius H, Massague J \& Niehrs C 1999 Silencing of TGF-beta signalling by the pseudoreceptor BAMBI. Nature 401 480-485.

Phillips DJ 2000 Regulation of activin's access to the cell: why is mother nature such a control freak? Bioessays 22 689-696.

Phillips DJ \& de Kretser DM 1998 Follistatin: a multifunctional regulatory protein. Frontiers in Neuroendocrinology 19 287-322.

Qian SW, Burmester JK, Tsang L-S, Weatherbee JA, Hinck AP, Ohlsen DJ, Sporn MB \& Roberts AB 1996 Binding affinity of transforming growth factor beta for its type II receptor is determined by the C-terminal region of the molecule. Journal of Biological Chemistry 271 30656-30662

Scheufler C, Sebald W \& Hulsmeyer M 1999 Crystal structure of human bone morphogenetic protein-2 at $2.7 \AA$ resolution. Journal of Molecular Biology 287 103-115.

Schlunegger MP \& Grütter MG 1992 An unusual feature revealed by the crystal structure of transforming growth factor-beta 2. Nature 358 430-434.

Schneyer AL, Hall HA, Lambert-Messerlian G, Wang QF, Sluss P \& Crowley WF Jr 1996 Follistatin-activin complexes in human serum and follicular fluid differ immunologically and biochemically. Endocrinology 137 240-247.

Shimonaka M, Inouye S, Shimasaki S \& Ling N 1991 Follistatin binds to both activin and inhibin through the common subunit. Endocrinology 128 3313-3315.

Sidis Y, Schneyer AL, Sluss PM, Johnson LN \& Keutmann HT 2001 Follistatin: Essential role for the $\mathrm{N}$-terminal domain in activin binding and neutralization. Journal of Biological Chemistry 276 17718-17726.

Ueno N, Ling N, Ying S-Y, Esch F, Shimasaki S \& Guillemin R 1987 Isolation and partial characterization of follistatin: A singlechain $\mathrm{Mr}$ 35,000 monomeric protein that inhibits the release of follicle-stimulating hormone. PNAS 84 8282-8286.

Vale W, Vaughan J, Yamamoto G, Bruhn T, Douglas C, Dalton D, Rivier C \& Rivier J 1983 Assay of corticotropin releasing factor. Methods in Enzymology 103 565-577.

Vale W, Rivier J, Vaughan J, McClintock R, Corrigan A, Woo W, Karr D \& Spiess J 1986 Purification and characterization of an FSH releasing protein from porcine ovarian follicular fluid. Nature 321 776-779.

Vaughan JM \& Vale WW 1993 Alpha 2-macroglobulin is a binding protein of inhibin and activin. Endocrinology 132 2038-2050.

Wang Q, Keutmann HT, Schneyer AL \& Sluss PM 2000 Analysis of human follistatin structure: identification of two discontinuous $\mathrm{N}$-terminal sequences coding for activin A binding and structural consequences of activin binding to native proteins. Endocrinology 141 3183-3193.

Wrana JL \& Attisano L 2000 The Smad pathway. Cytokine Growth Factor Reviews 11 5-13.

Wrana JL, Attisano L, Wieser R, Ventura F \& Massague Ji 1994 Mechanism of activation of the TGF-beta receptor. Nature $\mathbf{3 7 0}$ 341-347.

Wuytens G, Verschueren K, de Winter JP, Gajendran N, Beek L, Devos K, Bosman F, de Waele P, Andries M, van den Eijnden-van Raaij AJ, Smith JC \& Huylebroeck D 1999 Identification of two amino acids in activin A that are important for biological activity and binding to the activin type II receptors. Journal of Biological Chemistry 274 9821-9827.

Received 2 August 2002

Accepted 7 October 2002 